\title{
Exploring the Use of Self-Regulation Strategies in Programming with Regard to Learning Styles
}

\author{
Ünal Çakiroğlu ${ }^{1}$ \\ Betül Er² \\ Nursel Uğur ${ }^{3}$ \\ Esra Aydoğdu ${ }^{3}$ \\ ${ }^{1}$ Karadeniz Technical University \\ ${ }^{2}$ Agri University \\ ${ }^{3}$ Ministry of Education
}

DOI: $10.21585 / \mathrm{ijcses.v2 \textrm {i } 2 . 2 9}$

\begin{abstract}
This study attempts to understand the relationship between learning styles and self-regulated learning of preservice computer teachers in a programming course. Students' strategies for self-regulation with regard to their learning styles were assessed on the basis of qualitative data in terms of programming course. The Turkish version of Felder-Soloman learning style inventory was used to identify the students' learning styles and interviews were conducted to evaluate students' SRL strategies in programming. The results suggest that the characteristics of learning styles are somewhat related to self-regulation strategies. Time management was identified as a leading self-regulation strategy among learning styles, while shortcomings regarding target setting and self-efficacy strategies were prominent with almost all learning styles. Characteristics of other selfregulation strategies do not directly match with expected behaviors of learning styles in the context of learning programming. It is hoped that the study may shed light for instructors and instructional designers to design more appropriate settings for teaching programming taking learning styles in to consideration.
\end{abstract}

Keywords: self-regulated learning, learning styles, programming

\section{Introduction}

Computer programming is considered as a challenging course given the extensive set of knowledge and skills through the years (Bennedsen and Caspersen, 2008). Researchers often addressed that students struggle in the transition from introductory level programming to more advanced level. This is because in programming learning processes, students need to use various cognitive and metacognitive strategies to control and regulate their own learning (Brennan and Resnick, 2012; Hwang, Liang, and Wang, 2016). Numerous studies indicated that learning programming cannot be confined in the classroom only, and emphasize the need for applicable work for outside the classroom (Azevedo and Hadwin, 2005; Kozlowski and Bell, 2006; Wiedenbeck, LaBelle and Kain, 2004). Accordingly, investigating metacognitive processes underlying the learning programming has gained more attention. Thus, prior work in teaching programming pedagogy has focused on some problem solving strategies and techniques for overcoming difficulties in teaching programming (Lau and Yuen, 2011; Nam, Kim and Lee, 2010; Saeli et al., 2011).

In this circumstance, some researchers address greater involvement in the learning process and students' responsibility in their learning (Akpinar and Altun, 2014; Lye and Koh, 2014). In order to manage their learning; Self-regulated Learning (SRL) enables students to be active in the learning process while developing programming skills (Zimmerman, 2008). In this circumstance, specific SRL strategies are required to perform the programming tasks (Armstrong, 1989). It is evident that students who use these strategies can perform high in the process of learning programming (Alharbi et al., 2014; Falkner et al., 2014). Since programming requires self-regulation, many efforts are ongoing about developing self-regulation for programming. In this context, perspectives about how SRL arise in learning programming are discussed in the following section.

\subsection{Self-Regulation in Programming}

SRL allows students to be active and to direct their learning (Fernández et al., 2012; Zimmerman, 2002). Researchers have reached a consensus that students' SRL strategies have been positively related to their 
achievements (Artino, 2008; Artino, 2009; Lee, Shen, and Tsai, 2010; Liaw and Huang, 2013; Paechter, Maier and Macher, 2010; Pintrich, 2000; Puzziferro, 2008; Wang, Shannon and Ross, 2013). In general, the activities in the learning processes are considered as mediators between students, contexts, and achievement within SRL strategies (Pintrich, 2004). Safari and Hejazi (2017) argued that self-regulated learners can get advantage of their own learning because they know how to apply the acceptable actions in order to reach the goals. In the educational context; SRL strategies are seen in the dimensions of self-evaluation, organization, and transformation; goal setting and planning; seeking information, keeping records, and monitoring; environment structuring; self-consequences; rehearsing and memorizing; seeking social assistance; and reviewing records are used (Pintrich and DeGroot, 1990; Schunk and Zimmerman, 1998; Zimmerman, 2002; Zimmerman and Martinez-Pons, 1990).

In programming learning domain self-regulation arguably plays a key role in facilitating the development of major skills of problem solving such as logical thinking and reasoning, and helps students to manage their learning process during programming (Ramalingam, LaBelle and Wiedenbeck (2004). Some studies suggest that, self-regulated learners can find a number of ways to achieve the goals in programming learning process (Bergin, Reilly and Traynor 2005; Kumar et al. (2005). In this sense, some recent studies suggest planning, selfevaluation and self-monitoring (Falkner, Vivian, and Falkner, 2014; Falkner, Szabo, Vivian, and Falkner, 2015; $\mathrm{Li}, \mathrm{Ko}$, and $\mathrm{Zhu}, 2015$ ) are prominent strategies to achieve learning objectives in programming. Also, selfefficacy is considered as one of the main strategies of SRL which keeps students on track in learning programming (Kuo, Wu and Lin, 2013; Ramalingam et al., 2004; Wiedenbeck, 2005). Self-satisfaction is another factor which is emphasized by Kuo, Wu and Lin (2013) in their model. In addition, a recent study suggests that designing instruction through self-regulation skills for programming courses enhances problem solving skills (Loksa et al., 2016).

On the other hand; Hui and Umar (2010) highlighted some individual characteristics, such as learning styles and Wiedenbeck (2005) addressed previous programming experience and knowledge of organization were also important for learning programming. The fact that learning styles as processing information can certainly affect students' progress and their programming performances. In this context, the recent studies frequently reference to learning styles to understand the progression in learning programming.

\subsection{Learning Styles in Programming}

Safari and Hejazi (2017) point out that one of the learning obstacles in classroom is the lack of coordination between the instructional methods and the learning styles. Learning styles which are related to the way of students' information processing skills may influence to the student's performance in introductory programming' (Norwawi, Abdusalam, Hibadullah, and Shuaibu; 2009). When students are aware of their own different styles, they can learn better. Research studies indicate that matching learning styles with teaching methods provide high academic achievements. For instance, Alharbi et al. (2011) reported that some of the students in computer science programs are not aware of their SRL, and that they do not know how to apply SRL strategies in the learning process. Some other studies indicated that students with different learning styles prefer to use different SRL strategies (Shannon, 2008) and stating a relationship between SRL and learning styles may promote learning on the part of students (Safari and Hejazi, 2017). It can be considered that in the process of learning programming, students with different learning styles may follow or develop different self-regulation strategies. Thus, instructors should create authentic learning environments by being familiar with individual students' learning styles.

\subsection{Considering SRL with regard to Learning Styles}

It is known that student- centred educational paradigms place a high level of responsibility on learners to control and regulate their personal learning processes. It is also crucial to take individual differences into consideration in instructional processes (Das, 2015). Emphasizing the responsibility students' own learning, Paris and Winograd (2001) suggest promoting self-regulatory learning strategies. Being aware of the students' learning styles, teachers could help them to know their learning habits, and help them to apply better learning strategies within this responsibility. Since in problem solving in problem solving process acquired by self-regulated strategies (Zhang et al,2006), learning style as the characteristic cognitive, affective and psychological behaviors may serve as how learners perceive, interact with and respond to the learning environment (Keefe, 1988). Thus, within the student-centred paradigm, understanding students' preferences and the self-regulated learning strategies together may facilitate their learning process. In a study focusing on the relationships between SRL and learning style, Man-Chih, (2006) documented that since self-regulation provides learners with a role in 
decision-making; it is in an accord with converging learners' styles. Lavasani et al (2011) also found selfregulated learners using metacognitive strategies to get advantage of learning process which is in line with the feature of the diverging learners. Gülbahar (2005) referring to the SRL, argued that any student can adapt learning processes, activities and techniques, if he/she is able to understand his/her own learning styles and also be aware of his experiences.

\subsection{Aim of the Study}

While prior work has investigated many aspects of programming in terms of the role of self-regulation, more detailed investigation of the relationship between self-regulated learning and learning styles in the field of programming is needed. In order to facilitate learning, instructors should provide an easy way for students to discover their own characteristics. Thus, exploring the self-regulatory mechanisms regarding the learning styles would reveal the nature of psychological processes essential to the initiation, maintenance, and may be termination of learning in programming. So, this paper is hoped to contribute to understanding the relationships between learning styles and self-regulated learning strategies in the field of programming in higher education.

In line with the overall purpose of the study, the following research question was directed: How students' selfregulation strategies differentiate in terms of their learning styles in the context of programming learning process?

\section{Method}

A Turkish version of the Felder-Soloman's learning style inventory (LSI-T) coupled with a semi structured interview was applied to answer the research questions. The results from the interviews were then categorized and interpreted regarding the students' learning styles.

\subsection{Participants}

The study was carried out in a programming language course at the Computer and Instructional Technologies Department of a major university in Turkey. The participants were 57 pre-service computer teachers $(29$ male, 28 female) between the ages of 18 and 24. The participants have basic computer literacy skills, and limited prior programming knowledge. It was the first time they were receiving an introductory programming course. After, determining the learning styles of all students, 8 students (4 male 4 female) from all learning styles were interviewed.

\subsection{Instrumentation}

\subsubsection{LSI-T}

To identify students' learning styles, the Turkish language version of Felder and Soloman's Index of Learning Styles inventory was administered. Felder-Soloman index is one of the most widely used inventories in teaching programming, reflecting the skills required for learning programming. Felder and Soloman (1998) in their learning style model categorized learners according to four main characteristics, and classified the learning styles as: active-reflective; sensing-intuitive; visual-verbal; and sequential-global. While active learners prefer learning by doing or actively participating in work and prefer social interaction, reflective learners think about the task first. It means they prefer thinking quietly about information rather than be interactively engaged in learning activities. Intuitive learners would be more comfortable managing their own learning, so they prefer finding learning possibilities, discovery, innovation, and abstractions. In contrast, sensing learners deal with facts and concepts, example-based, concrete learning (Dille and Mezack 1991). In addition, verbal learners get more out of words than from visual representations and the global learners learn in large jumps by seeking out the "big picture" rather than learning in the traditional, sequentially organized college course.

The Index of Learning Styles (ILS) (Felder and Soloman, 1991) is a 44-question survey based on a learning style model. The validity and reliability of the index have been verified by a number of studies (Felder and Spurlin, 2005; Litzinger et al., 2007; Zywno, 2003). One reason selecting this inventory is the potential of the inventory for determining whether the learner has a strong, moderate, or low preference on the identifiers of the learner styles. The index was translated into Turkish and validity and reliability analyses were provided (Büyüköztürk, Akgün, Özkahveci and Demirel, 2004). The LSI consists of 44 two-part ('a' and 'b') items. Each item comes with two options, where ' $a$ ' represents active, sensing, visual, sequential learning styles while ' $b$ ' suggests reflective, intuitive, verbal and global ones. 
The inventory was used in previous programming teaching studies. For instance, Chen and Lin (2011) used the inventory to identify learning styles at the beginning of programming instruction. In a similar vein, Norwawi Abdusalam and Hibadullah (2009) applied the Felder-Soloman learning styles inventory with master's students prior to the beginning of the course.

\subsubsection{Interviews}

Semi-structured interviews were conducted to gather the perceptions about students' SRL strategies. The interview questions were developed on the basis of the strategies referring to the SRL definitions (Pintrich, Smith, Garcia and McKeachie, 1991). The strategies were in relation with task value, external target orientation, target setting, self-efficacy, self-reflection, repetition, peer learning, time management, and effort regulation. When formulating the semi-structured interview questions, various SRL scales focusing on these strategies were also reviewed, within the framework of the programming languages course. The selected interview questions are presented in Appendix 1.

\subsection{Data Analysis}

To find mean scores for each learning styles, instances where option 'a' was chosen were coded 1, and the instances with option ' $b$ ' were coded 2 . Referring to the original inventory mean scores in the 11 to 16 range represent active, sensing, visual and sequential learners. On the other hand, mean scores in the 17 to 22 range represent reflective, intuitive, verbal, and global learners (Arslan and Aksu, 2006).

The data obtained through the interviews, in turn, were analyzed through content analysis. The interviews were transcribed into text, followed by thematic analysis based on expressions in common statements to define the main themes. First, initial codes were identified by two coders. After examining the responses, the coders produced tentative thematic units. Thereafter relationships, similarities and differences between the codes assigned by both coders were reviewed and categorized, culminating in the construction of the themes in a manner to ensure perfect concurrence among the coders, regarding the final themes. Moreover, direct quotations in association with the learning styles were presented with special attention being paid to maintain the meaning.

\section{Results}

The results are presented regarding the relationship between the learning styles and the use of self-regulation strategies. In this context, a two-dimensional tabular presentation is used in order to express the codes related to the strategies reflecting learning styles. Participants are assigned as $S_{n}$ according to their learning styles. The interviewed students' perceptions about the SRL strategies in the context of the programming course were presented in line with their different learning styles. The perceptions about the strategies used in "task value" category are shown in Table1.

Table 1. Strategies in task value category

\begin{tabular}{|c|c|c|c|c|c|c|c|c|c|}
\hline & \multirow[b]{2}{*}{ Strategies } & \multicolumn{8}{|c|}{ Students' Learning Styles } \\
\hline & & 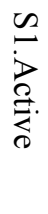 & 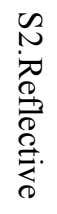 & 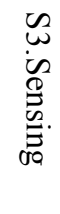 & 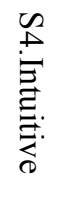 & 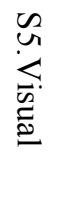 & $\begin{array}{l}\mathscr{L} \\
\stackrel{\alpha}{\alpha} \\
\stackrel{0}{0} \\
\stackrel{0}{0}\end{array}$ & 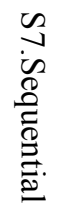 & $\begin{array}{l}\infty \\
\infty \\
\mathscr{\Omega} \\
\stackrel{0}{0} \\
\stackrel{\sigma}{0}\end{array}$ \\
\hline \multirow{4}{*}{ Task Value } & $\begin{array}{l}\text { Making practical use of the } \\
\text { profession }\end{array}$ & & $\sqrt{ }$ & $\sqrt{ }$ & $\sqrt{ }$ & $\sqrt{ }$ & & $\sqrt{ }$ & \\
\hline & $\begin{array}{l}\text { Providing associations with } \\
\text { various fields }\end{array}$ & $\sqrt{ }$ & $\sqrt{ }$ & $\sqrt{ }$ & $\sqrt{ }$ & $\sqrt{ }$ & $\sqrt{ }$ & $\sqrt{ }$ & \\
\hline & $\begin{array}{l}\text { Considering it as a means to } \\
\text { enhance intelligence }\end{array}$ & $\sqrt{ }$ & & $\sqrt{ }$ & & & & & \\
\hline & Not attaching value & & & & & $\sqrt{ }$ & & & $\sqrt{ }$ \\
\hline
\end{tabular}

Table 1 show that the majority of the students believe that; they will use programming experience in their professional life, and they consider programming as the one of the basic competencies of being a computer 
teacher. All students noted that programming logic is related with a number of distinct fields. A participant with intuitive style expressed this point by saying "It can be used in a number of fields. We use the logic unwittingly, even in our daily lives". Only the students with active and sensing learning styles deemed the programming course as a means to enhance intelligence, whereas those of visual and global styles did not address any taskvalue point with respect to the programming course.

Students' views regarding the "external target orientation" are presented in Table 2.

Table 2. Strategies in external target orientation category

\begin{tabular}{|c|c|c|c|c|c|c|c|c|c|}
\hline & \multirow[b]{2}{*}{ Strategies } & \multicolumn{8}{|c|}{ Students' Learning Styles } \\
\hline & & 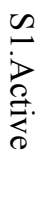 & 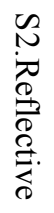 & 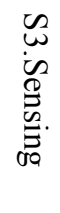 & 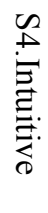 & $\begin{array}{l}\infty_{0}^{\infty} \\
\vdots \\
\vdots \\
0 \\
0 \\
0\end{array}$ & $\begin{array}{l}\mathscr{2} \\
2 \\
0 \\
0 \\
0 \\
0\end{array}$ & 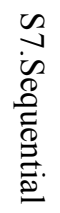 & 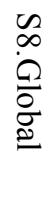 \\
\hline \multirow{4}{*}{$\begin{array}{c}\text { External } \\
\text { Target } \\
\text { Orientation }\end{array}$} & Passing the course & $\sqrt{ }$ & $\sqrt{ }$ & & $\sqrt{ }$ & & $\sqrt{ }$ & $\sqrt{ }$ & $\sqrt{ }$ \\
\hline & $\begin{array}{l}\text { Engaging in high-level } \\
\text { programming }\end{array}$ & & $\sqrt{ }$ & & & & & $\sqrt{ }$ & \\
\hline & Learning the basics & $\sqrt{ }$ & & $\sqrt{ }$ & & $\sqrt{ }$ & & & \\
\hline & $\begin{array}{l}\text { Developing programs with no } \\
\text { support }\end{array}$ & & $\sqrt{ }$ & & & & & & \\
\hline
\end{tabular}

A glance at the students' aims and intentions associated with the programming course indicate that only sensing and visual students intended to pass the course. Indeed, the ones with intuitive, verbal, and global styles expressed that passing the course is their main aim with the course. The ones with reflective and sequential style students added the ability to engage in high-level programming. In addition the active, sensing, and visual style students noted the expectation to learning the basics of programming as well. The student with the reflective style, in turn, mentioned the importance of writing programs without getting help.

Strategies expressed with the "target setting learning" are summarized in Table 3.

Table 3. Strategies in Target Setting Category

\begin{tabular}{|c|c|c|c|c|c|c|c|c|c|}
\hline & \multirow[b]{2}{*}{ Strategies } & \multicolumn{8}{|c|}{ Students' Learning Styles } \\
\hline & & 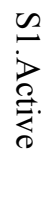 & 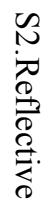 & $\begin{array}{l}\underset{\omega}{\omega} \\
\underset{\infty}{\Phi} \\
\stackrel{\infty}{\mathscr{O}} \\
\stackrel{\infty}{\Xi} .\end{array}$ & 足 & 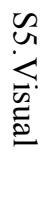 & $\begin{array}{l}\mathscr{2} \\
\stackrel{\infty}{0} \\
\stackrel{0}{0} \\
\stackrel{0}{0}\end{array}$ & 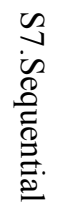 & $\begin{array}{l}\infty \\
\infty \\
\stackrel{2}{0} \\
0 \\
0 \\
0\end{array}$ \\
\hline \multirow{5}{*}{ Target Setting } & Completing the program & & & $\sqrt{ }$ & $\sqrt{ }$ & $\sqrt{ }$ & $\sqrt{ }$ & & $\sqrt{ }$ \\
\hline & Getting ahead of the peers & $\sqrt{ }$ & & & & & $\sqrt{ }$ & & \\
\hline & Developing different solutions & & & & & & $\sqrt{ }$ & & \\
\hline & $\begin{array}{l}\text { Comprehending programming } \\
\text { logic }\end{array}$ & $\sqrt{ }$ & & & & & & & \\
\hline & Setting no target & & & & & & & $\sqrt{ }$ & \\
\hline
\end{tabular}

A substantial number of the students (sensing, intuitive, visual, verbal, global) intend to complete the program they are writing, without any bugs. Furthermore, the students with verbal style include getting ahead of the peers and developing unique solutions. Those with the active style intend to grasp at least the logic of the program. Sequential style student stated that she have no targets. Such targets set by students before venturing with the program usually prevent dropping out of the endeavor prematurely.

Self-efficacy is considered one of the most important category concerning self-regulating learning. In this context, the students' perspectives about the strategies related to self-efficacy are expressed in Table 4. 
Table 4. Strategies in self-efficacy category

\begin{tabular}{|c|c|c|c|c|c|c|c|c|c|}
\hline & \multirow[b]{2}{*}{ Strategies } & \multicolumn{8}{|c|}{ Students' Learning Styles } \\
\hline & & 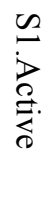 & 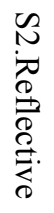 & $\begin{array}{l}\underset{\omega}{\omega} \\
\underset{\infty}{\Phi} \\
\stackrel{\infty}{\mathscr{O}} \\
\stackrel{\infty}{\Xi} .\end{array}$ & 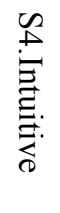 & 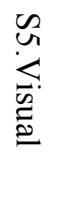 & 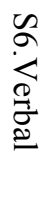 & 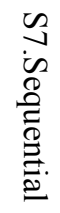 & $\begin{array}{l}\infty \\
\infty \\
\stackrel{\Omega}{Q} \\
\stackrel{0}{0} \\
\stackrel{0}{0}\end{array}$ \\
\hline \multirow{5}{*}{ Self-Efficacy } & $\begin{array}{l}\text { Providing a holistic view for } \\
\text { the problem }\end{array}$ & & & & & & & & $\sqrt{ }$ \\
\hline & Employing distinct solutions & & $\sqrt{ }$ & & & & $\sqrt{ }$ & & \\
\hline & Employing common solutions & $\sqrt{ }$ & & & & & & & \\
\hline & $\begin{array}{l}\text { Writing brief and easy-to- } \\
\text { decipher programs }\end{array}$ & & & & $\sqrt{ }$ & $\sqrt{ }$ & $\sqrt{ }$ & & \\
\hline & Adding a visual perspective & & & & $\sqrt{ }$ & & & & \\
\hline
\end{tabular}

Some students with global style had a preference for holistic approaches. Moreover, those with reflective and verbal styles emphasized confidence in their ability to find distinctive solutions to the problem, while those with the active style noted the advantages of applying common solutions. Those with intuitive, visual, and verbal styles expressed their ability to write brief and comprehensible programs, while those with the intuitive style exclusively referred to the ability to add a visual element. In this sense, S4 expressed that "If the program is about a ball, the color of that ball is important for me." The ones with the visual style, on the other hand, voiced their confidence in perseverance in the face of problems. The student with the sensing style surprisingly did not note any strategy regarding self-efficacy. Students' views with respect to self-reflection are presented in Table 5.

Table 5. Strategies in Self-Reflection Category

\begin{tabular}{|c|c|c|c|c|c|c|c|c|c|}
\hline & \multirow[b]{2}{*}{ Strategies } & \multicolumn{8}{|c|}{ Students' Learning Styles } \\
\hline & & 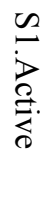 & 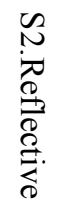 & 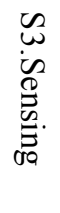 & 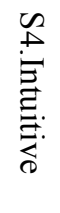 & 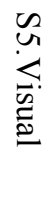 & $\begin{array}{l}\mathscr{2} \\
\stackrel{0}{0} \\
\stackrel{0}{0} \\
\stackrel{0}{0}\end{array}$ & 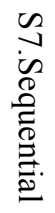 & $\begin{array}{l}\infty \\
\stackrel{\infty}{\Omega} \\
\stackrel{\Omega}{0} \\
\stackrel{0}{0}\end{array}$ \\
\hline \multirow{10}{*}{ Self-Reflection } & $\begin{array}{l}\text { Reflecting bugs incurred } \\
\text { in the program }\end{array}$ & $\sqrt{ }$ & $\sqrt{ }$ & $\sqrt{ }$ & $\sqrt{ }$ & $\sqrt{ }$ & $\sqrt{ }$ & $\sqrt{ }$ & $\sqrt{ }$ \\
\hline & $\begin{array}{l}\text { Forgetting programming } \\
\text { approaches }\end{array}$ & $\sqrt{ }$ & & $\sqrt{ }$ & & & & & $\sqrt{ }$ \\
\hline & $\begin{array}{l}\text { Difficulties in directing } \\
\text { attention }\end{array}$ & & $\sqrt{ }$ & & & & & & \\
\hline & $\begin{array}{l}\text { Not taking time for } \\
\text { programming }\end{array}$ & & & & & $\sqrt{ }$ & $\sqrt{ }$ & & \\
\hline & Getting bored & & & $\sqrt{ }$ & & & $\sqrt{ }$ & & \\
\hline & Checking incorrect codes & & $\sqrt{ }$ & $\sqrt{ }$ & & & $\sqrt{ }$ & & $\sqrt{ }$ \\
\hline & Repeating & $\sqrt{ }$ & & $\sqrt{ }$ & & & & & \\
\hline & Getting help & $\sqrt{ }$ & & $\sqrt{ }$ & $\sqrt{ }$ & $\sqrt{ }$ & $\sqrt{ }$ & $\sqrt{ }$ & $\sqrt{ }$ \\
\hline & Trying different ways & & & $\sqrt{ }$ & & $\sqrt{ }$ & & & \\
\hline & Developing ambition & $\sqrt{ }$ & & & & & & & \\
\hline
\end{tabular}

All students noted that they experienced at least one bug when writing programs and those they checked the code to correct them. Those with a style other than reflective, on the other hand, expressed that they got help. The one with the sensing style expressed that "I often faced with errors. To overcome them, I either have to check the bugs or I get help from my friends." Other students with active, sensing, and global styles addressed that they sometimes have difficulty in how to find appropriate programming approaches. To overcome this problem, they noted the need to repeat certain structures. Visual and verbal style students on the other hand, referred to the inability to take time required for programming, as the leading problem they faced, while the ones with sensing 
or verbal styles expressed that they got bored when writing programs. In addition, the active style student expressed that she would get rather avid as she noticed the shortcomings, while the one with the sensing style noted her competence about trying different means to solutions. The views voiced with respect to repetition and peer learning strategies are expressed in Table 6 and Table 7 respectively.

Table 6. Strategies in repetition category

\begin{tabular}{|c|c|c|c|c|c|c|c|c|c|}
\hline & \multirow[b]{2}{*}{ Strategies } & \multicolumn{8}{|c|}{ Students' Learning Styles } \\
\hline & & 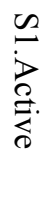 & 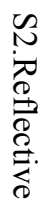 & 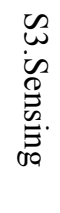 & 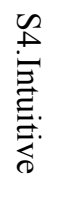 & 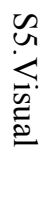 & $\begin{array}{l}\mathscr{2} \\
\stackrel{<}{0} \\
\stackrel{0}{0} \\
\stackrel{0}{0}\end{array}$ & 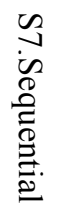 & $\begin{array}{l}\infty \\
\dot{Q} \\
\stackrel{0}{0} \\
\stackrel{0}{0}\end{array}$ \\
\hline \multirow{6}{*}{ Repetition } & $\begin{array}{l}\text { Taking notes about important } \\
\text { pieces of code }\end{array}$ & & $\sqrt{ }$ & & $\sqrt{ }$ & & & & $\sqrt{ }$ \\
\hline & $\begin{array}{l}\text { Developing solutions on } \\
\text { paper }\end{array}$ & $\sqrt{ }$ & $\sqrt{ }$ & $\sqrt{ }$ & & & $\sqrt{ }$ & & $\sqrt{ }$ \\
\hline & Reviewing sample programs & $\sqrt{ }$ & & & & $\sqrt{ }$ & & $\sqrt{ }$ & $\sqrt{ }$ \\
\hline & Trial and error on a computer & & & & $\sqrt{ }$ & $\sqrt{ }$ & & $\sqrt{ }$ & \\
\hline & $\begin{array}{l}\text { Developing and solving } \\
\text { similar questions }\end{array}$ & $\sqrt{ }$ & & & & & & & \\
\hline & Memorizing & & & $\sqrt{ }$ & & $\sqrt{ }$ & & & \\
\hline
\end{tabular}

When preparing for the exam, half of the students who have distinctive learning styles (active, visual, sequential, global) reviewed sample programs and took notes about the scripts. In this context, the student with visual style specified that "First of all, I check the sample applications and learn about the common forms. Then I try to write the software to understand the overall logic." Students with intuitive, visual, and sequential styles studied on exercises to get ready for the exams, while the rest prefer writing codes on paper. The student with active style said that she developed similar questions and tried to solve them. Those with sensing and visual styles memorized the pieces of scripts to prepare for the exams.

Table 7. Strategies in peer-learning category

\begin{tabular}{|c|c|c|c|c|c|c|c|c|c|}
\hline & \multirow[b]{2}{*}{ Strategies } & \multicolumn{8}{|c|}{ Students' Learning Styles } \\
\hline & & 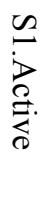 & 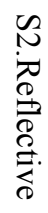 & $\begin{array}{l}\underset{\omega}{\omega} \\
\underset{\infty}{\Phi} \\
\stackrel{\infty}{\Xi} \\
\stackrel{\sigma}{\Xi}\end{array}$ & 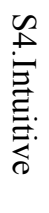 & 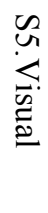 & $\begin{array}{l}\mathscr{2} \\
2 \\
0 \\
0 \\
0 \\
0\end{array}$ & 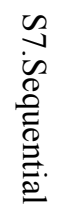 & $\begin{array}{l}\infty \\
\infty \\
\stackrel{\Omega}{0} \\
\stackrel{0}{0} \\
\stackrel{0}{0}\end{array}$ \\
\hline \multirow{4}{*}{ Peer Learning } & $\begin{array}{l}\text { Providing solutions for } \\
\text { errors }\end{array}$ & $\sqrt{ }$ & $\sqrt{ }$ & $\sqrt{ }$ & $\sqrt{ }$ & & $\sqrt{ }$ & & $\sqrt{ }$ \\
\hline & Doing homework & & $\sqrt{ }$ & & & & & & \\
\hline & Studying for exams & $\sqrt{ }$ & & & & & & $\sqrt{ }$ & $\sqrt{ }$ \\
\hline & Required no help & & $\sqrt{ }$ & & & $\sqrt{ }$ & & & \\
\hline
\end{tabular}

The students with reflective and visual learning styles addressed that they tried to refrain from getting help; yet they often get help from their peers in their efforts to solve the problems they often encounter. In addition, the students cooperate with their peers for doing homework as with the reflective style student noted, and during exam weeks as active sequential, and global style students mentioned.

Time-management of self-regulated strategies is generally associated with the classroom activities as well. In this context, the perspectives regarding the time-management are presented in Table 8. 
Table 8. Strategies in time management category

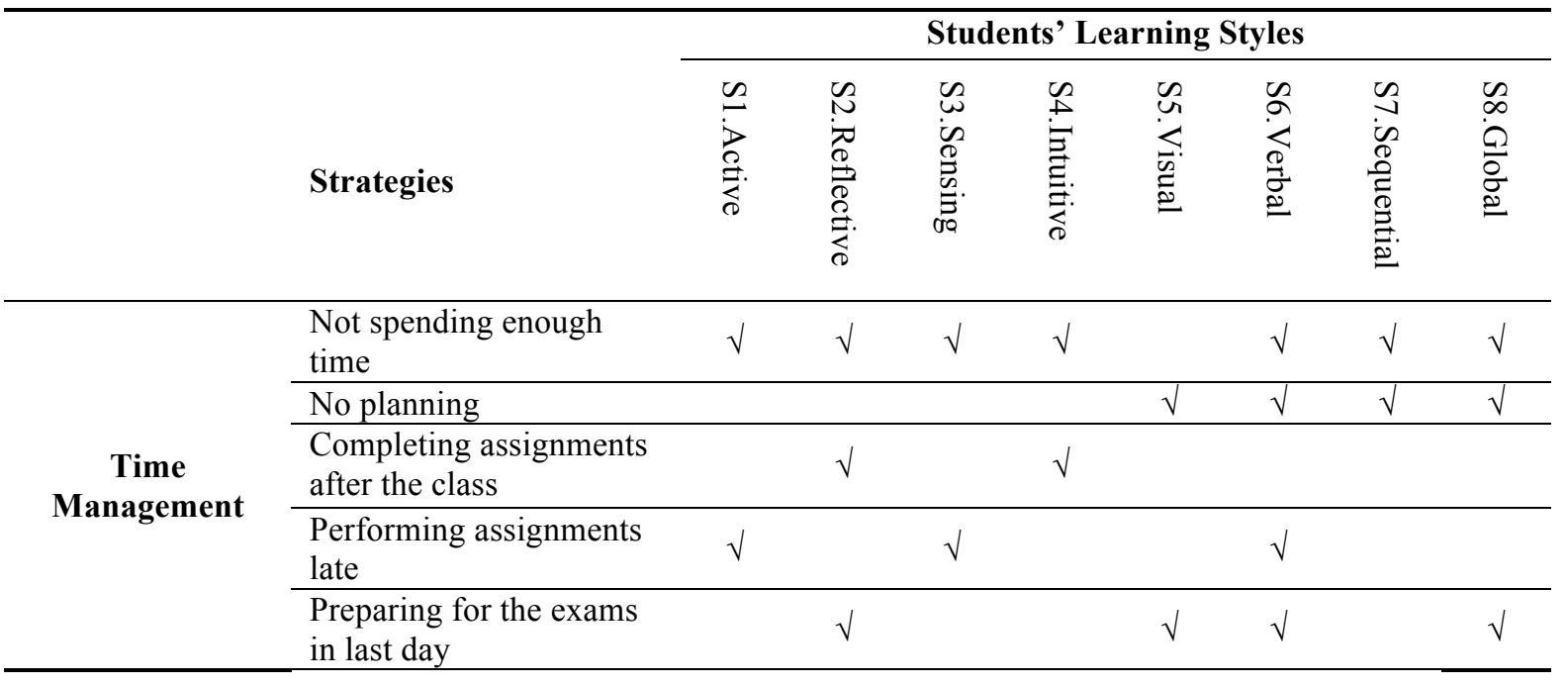

The students except the one with visual style noted insufficiency of the time devoted to the programming course. The ones with visual, verbal, sequential, and global styles, in particular, pointed out the lack of any planning for time-management for this course. The ones with reflective and intuitive styles completed the assignments right after class, while the ones with active, sensing, and verbal styles had a preference for waiting for the last period. Students with reflective, visual, verbal, and global styles addressed that they studied for the programming exams only on the last day before the exam. Participant having global learning style objective was only to pass the course, and expressed by commenting "I study for the exams on the very last day. It allows me to get a grade of 45." Views about "effort regulation" are shown in Table 9.

Table 9. Strategies in effort regulation category

\begin{tabular}{|c|c|c|c|c|c|c|c|c|c|}
\hline & \multirow[b]{2}{*}{ Strategies } & \multicolumn{8}{|c|}{ Students' Learning Styles } \\
\hline & & 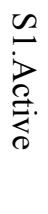 & 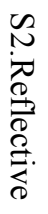 & 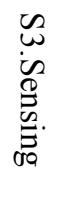 & 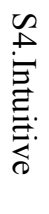 & 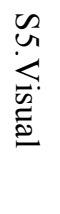 & 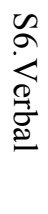 & 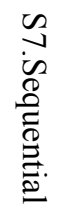 & $\begin{array}{l}\infty \\
\infty \\
\varrho \\
\stackrel{\Omega}{0} \\
\stackrel{0}{0}\end{array}$ \\
\hline \multirow{4}{*}{$\begin{array}{c}\text { Effort } \\
\text { Regulation }\end{array}$} & Having a break & $\sqrt{ }$ & $\sqrt{ }$ & $\sqrt{ }$ & $\sqrt{ }$ & $\sqrt{ }$ & $\sqrt{ }$ & & $\sqrt{ }$ \\
\hline & Seeking help & & & $\sqrt{ }$ & $\sqrt{ }$ & & $\sqrt{ }$ & & \\
\hline & Giving up completely & & & & & & & $\sqrt{ }$ & \\
\hline & $\begin{array}{l}\text { Getting motivated only } \\
\text { with the easier parts }\end{array}$ & & & & & & $\sqrt{ }$ & & \\
\hline
\end{tabular}

Most of the interviewees stated that they usually took a break with programming when they face any challenges to resume the efforts later on, while the one with the sequential style expressed that she completely gave up in such cases. She pointed out this by saying "I demotivated and give up if I fail to solve a problem." Moreover, the ones with the sensing, intuitive, and verbal learning styles noted getting help to overcome issues. The verbal style student expressed that she would be motivated by handling the easier parts of the program first, which would motivate her for the rest of the problem. The leading strategies employed by students who have different self-regulating learning strategies for programming course with regard to Felder and Soloman (1994) inventory are summarized in Figure 1. The figure was developed on the basis of positive perspectives with respect to a substantial portion of indicators concerning a given strategy. Overall, Figure 1 summarizes the perceptions about the self-regulation strategies employed by students with different learning styles in the context of learning programming. Also examples from active and sequential style students' artifacts are provided in Appendix2. 


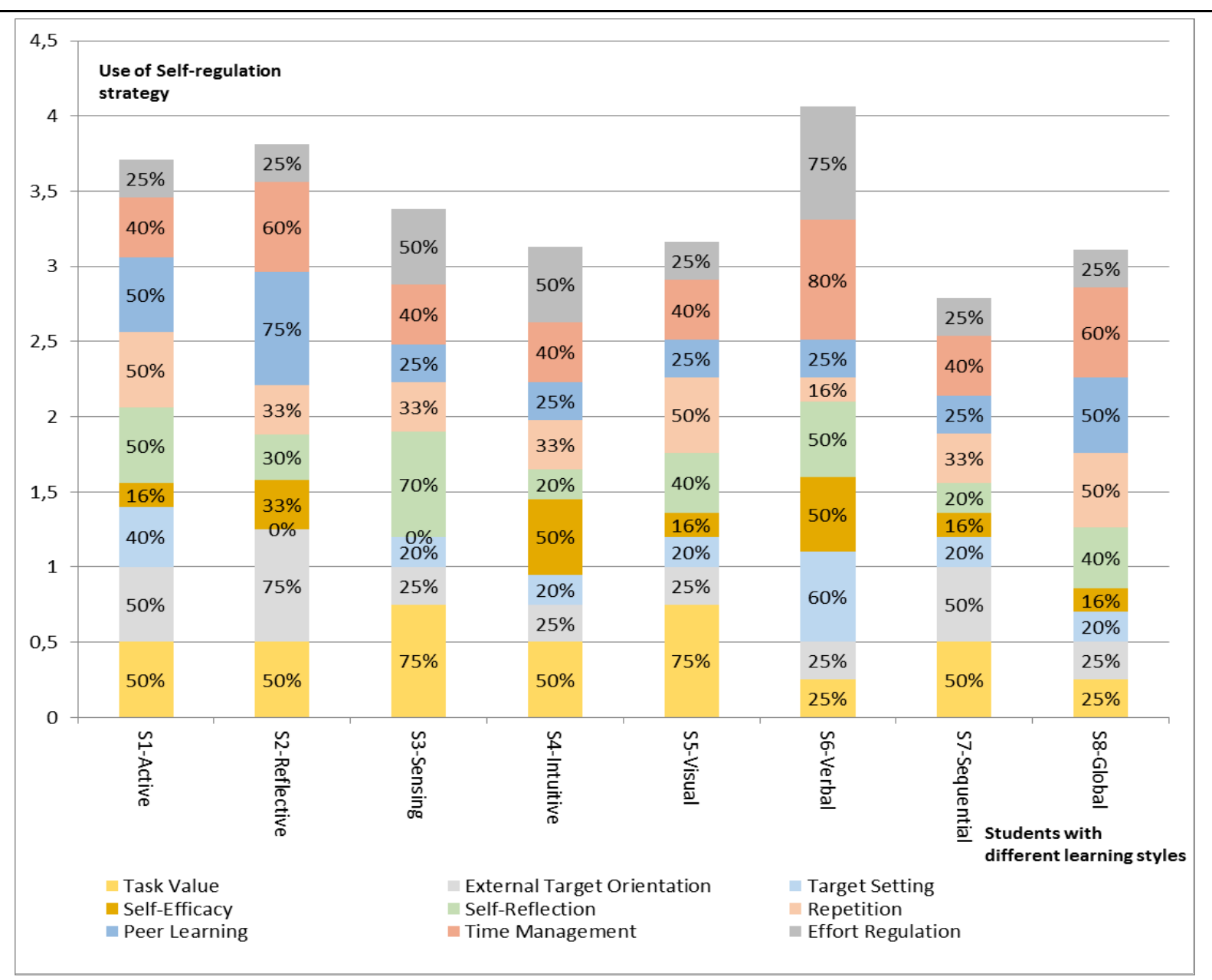

Figure 1. Use of self-regulating learning strategies with reference to their learning styles

Students' perceptions with regard to self-regulated learning strategies indicate that various learning styles are prominent in using some strategies. Yet, the ones with visual and sequential learning styles expressed clues about a rather limited set of indicators compared to the expressions of other students, while the ones with active and verbal styles voiced concrete statements concerning numerous indicators. Figure 1 reveals that students with visual, verbal, and global styles did not express any statements about the task value strategy, while the ones other than those with the active, reflective, and sequential strategies expressed that they somewhat provide external target orientation strategies. Furthermore, the target setting and self-efficacy strategies stand out as the ones where the concrete statements on part of the students were rarest. Students with active, sensing, and verbal learning styles expressed positive views about the self-reflection strategy, while students with other learning styles voiced positive views was only about a very limited set of items. On the other hand, participants with active, visual and global styles perceptions regarding the repetition strategy were explicitly positive. Students with active, reflective, and global strategies expressed clues concerning numerous indicators associated with the peer-learning strategy.

\section{Discussion}

Considering prior work, this study is based on the idea that students with various individual characteristics can exhibit different self-regulation strategies during learning programming. Felder-Soloman learning styles inventory is generally discussed with reference to four dimensions considering the similarities among the styles: sensing/ intuitive, visual/ verbal, active/ reflective, sequential/global. The result of this study indicated that peerlearning and external target orientation were prominent strategies in reflective learning style, while the sensing style students emphasized task value and self-reflection strategies. In the same vein, Das (2015) found a significant relationship between self regulated learning and cognitive styles. Students having different learning styles perceived in various extend of self-regulated strategies in this study. Relationships between the characteristics of learning styles and their perceptions about the self-regulated strategies are discussed in the following section. 


\subsection{Sequential / Global}

Students with a sequential learning style learn the knowledge offered, as a sequence of interrelated smaller parts. Global learners generally need to associate new knowledge with their preliminary knowledge and experience, before getting acquainted with the details of the topic. Sequential learners, on the other hand, can utilize specific details without embracing the topic as a whole. But they can have problems in grasping the connections the topic has with other fields and disciplines (Felder and Silverman, 1988). In the present study, student with sequential learning style expressed an emphasis on task value and external target orientation strategies. Students who employ a sequential learning style can associate the knowledge with their pre-existing knowledge. Hence, it is only natural that the task value and external target orientation strategies are emphasized by students who have sequential learning style, for whom motivation is considered a substantial factor in terms of self-regulating learning strategies employed. Student having a global learning style, in her turn, had emphasized the repetition, peer-learning and time management strategies. Also, students who have a global learning style can achieve lasting learning by associating the new knowledge with their previous experiences. One can find an emphasis on the repetition strategy curious for a student with global style. The repetition strategy which is based on memorizing and global learning style is all about associating meaning through experience.

\subsection{Active/Reflective}

Active learning process entails interactions with the external world, such as discussing, expressing, or testing the acquired knowledge. Active learners prefer to be engaged in physical activity, while the reflective ones choose contemplation about knowledge offered (Felder and Silverman, 1988). In the study, the student who had active learning style was positively perceived task value, external target orientation, self-reflection, repetition, and peer learning self-regulating learning strategies. Since active learning style is often about considerations with the external world, his emphasis on the external target orientation and peer learning strategies are not surprising, through the characteristics of this style. In addition, student who had reflective learning style highlighted the task value, external target orientation, and peer learning self-regulating learning strategies. Taking the emphasized strategies into consideration, one can refer to a positive relation between the learning style and time management, particularly in the light of the results observed with student with reflective learning style.

\subsection{Visual / Verbal}

According to Felder and Silverman (1988), the visual learners prefer to use visual elements such as images, diagrams, schemes and presentations for the presentation of knowledge, compared to verbal statements or written texts, while the verbal learners prefer verbal statements and written texts. In this study the student who had a visual learning style had also found the task value and repetition self-regulating learning strategies important. The students with a visual learning style do not need the repetition strategy to the extent the students with a verbal style do. In the same vein, the visual learner's emphasis on the repetition self-regulating learning strategy is considered to be surprising. Verbal learning style student emphasized target setting, self-efficacy, selfreflection, time management, and effort regulation strategies. Thus, it can be concluded that that time management and regulation strategies could be expected, while the repetition strategy was once again a surprise.

\subsection{Sensing / Intuitive}

Felder and Silverman (1988) in their learning style model defines sensing learning style having a preference for the knowledge directed at their senses and the intuitive learners are better with knowledge arising internally, from their own ideas. Student who had a sensing learning style in this study had addressed task value, selfreflection, and effort regulation self-regulating learning strategies. Students with sensing learning style are inclined to receive the knowledge directed towards their senses. In this context, emphasis on the effort regulation and task value strategies on part of the student with the sensing learning style may be a function of the perception with reference to her learning style. The student who had an intuitive learning style had emphasized the task value, self-efficacy, and effort regulation self-regulating learning strategies. The intuitive learners welcome the knowledge they can imagine internally in their minds, while the students with the intuitive learning style presented with a surprise in the form of the emphasis on effort regulation self-regulating learning strategy.

Overall, students with the active, reflective, and verbal learning styles presented different self-regulation strategies. These students evidently focus more on the self-regulation strategies, compared to the adherents of other learning styles. The perceived self-regulation strategies among students who have active, intuitive, and 
sequential learning styles does not lead to substantial differences. In terms of the programming learning process, planning is pervasive throughout problem solving, guiding the direction that programmers take. Few participants were expected to exhibit planning, given their inexperience. The lack of emphasis on planning with respect to time management in particular, on part of students of some learning styles (visual/ verbal, sequential/global) is noteworthy. In the present study, students with a wide range of learning styles were found to exhibit skills such as making associations with various fields, passing the course which can be listed among the motivational factors. The similar results reached by Das (2015) revealed a significant relationship between self regulated learning and cognitive styles of secondary school students. There is also a consistency between the findings of this study and prior studies about the relationship between learning styles and self-regulation strategies. For instance, the study by Kumar et al. (2005) indicates that programmers who received self-regulated-based treatment outperformed those who did not. Safari and Hejazi (2017) examined the relationship between the Kolb learning styles -converging, diverging, assimilating, and accommodating- with the participants' self-regulation skills. The results showed a positive relationship between each learning styles and self-regulation skills.

The study has also some limitations. The study was carried out with a limited size of sample selected from those who received the Programming Languages course. With a sample size of 8 it was difficult to generalize the power needed to precisely identify relations. Yet, the data gathered allow us to reach to certain conclusions regarding the role of students' work and their individual characteristics in a qualitative manner. The data from interviews provided the discussions about the nature of the strategies.

\section{Conclusion and Recommendations}

The analysis sought to reveal the association between the learning style and the self-regulated learning in terms of learning programming, with reference to the views expressed by students. The results suggest that learning styles are somewhat related to self-regulation strategies. In particular, perceptions of the students with active/reflective and sequential/global learning styles with reference to their SRL strategies considerably reflect the characteristics of those learning styles.

On the other hand, students with visual/verbal learning styles did not strongly reflect those characteristics. Some of the students in visual/verbal learning styles in turn, surprisingly expressed perceptions which are deemed to be in contrast to those expected of their learning styles. Time management was identified as a leading strategy among learning styles, while shortcomings regarding target setting and self-efficacy were prominent with almost all learning styles. Thus, one can argue that learning styles and perceptions about SRL strategies are somewhat related to each other. Nonetheless, some external factors may still affect this relationship. In this sense, in the process of teaching programming, it is observed that directing students' SRL strategies is not an easy task. In other words, the reflections of students' learning styles may not always match with their strategy use in the learning process. In such cases, programming instructors may be compelled to find new ways for customizing the learning process.

The present study investigated differentiation of learning styles with reference to qualitative interview data. This allowed the association of the characteristics of learning styles, and the perceptions about the basic indicators of self-regulation. Despite these and many other limitations affecting to the generalizability of our results, the results may still be considered as a first step in understanding the relationship between learning styles and selfregulation in programming. Since SRL strategies offer the potential of facilitating learning programming; the results of this study suggest taking note of individual characteristics to inform the application of the strategies is noteworthy. We hope that the results provide some insights into the self-regulated learning in a higher education programming instruction.

\section{References}

Akpınar, Y., Altun, Y. (2014). The need for programming education at the schools of an information society. Elementary Education Online, 13(1), 1-4.

Alharbi, A., Henskens, F., and Hannaford, M. (2014). Personalised learning object system based on selfregulated learning theories. International Journal of Engineering Pedagogy, 4(3), 24-35. http://dx.doi.org/10.3991/ijep.v4i3.3348

Alharbi, A., Paul, D., Henskens, F., and Hannaford, M. (2011). An investigation into the learning styles and selfregulated learning strategies for computer science students. In Proceedings Ascilite. Association for Computing Machinery (ACM) \& IEEE Computer Society (IEEE-CS), 2008. 
Armstrong, A. (1989). The development of self-regulation skills through the modeling and structuring of computer programming. Educational Technology Research and Development, 37(2), 69-76.

Arslan, B., Aksu, M. (2006). A descriptive study on the learning style profiles of engineering students of the Middle East Technical University (METU). Education and Science, (31), 141.

Artino, A.R. (2008). Motivational beliefs and perceptions of instructional quality: Predicting satisfaction with online training. Journal of Computer Assisted Learning, (24), 260-270.

Artino, A.R. (2009). Think, feel, act: motivational and emotional influences on military students' online academic success. Journal of Computing in Higher Education, (21), 146-166.

Azevedo, R.., Hadvin, A. (2005). Scaffolding self-regulated learning and metacognition-implications for the design of computer-based scaffolds. Instructional Science, (33), 367-379.

Bennedsen, J. and Carpersen, M. E. (2008). Exposing the programming process. Bennedsen, J.,Carpersen, M. E. ve Kolling, M. (Eds.). Reflection on the theory of programming: Methods and implementation, 6-16. New York: Springer Berlin Heidelberg.

Bergin, S., Ronan R., Desmond, T. (2005). Examining the role of self-regulated learning on introductory programming performance. In Proceedings of the First International Workshop on Computing Education Research, (pp.81-86). Seattle, WA, USA.

Brennan, K., Resnick, M. (2012). Using artifact-based interviews to study the development of computational thinking in interactive media design. Paper presented at annual American Educational Research Association meeting, Vancouver, BC, Canada.

Büyüköztürk, Ş., Akgün, Ö. E., Özkahveci, Ö., and Demirel, F. (2004) .Validity and reliability study of Turkish version of the scale of motivation and learning strategies. Theory and Practice in Educational Sciences, 4(2), 207-239.

Chen, C. L., \& Lin, J. M. C. (2011). Learning styles and student performance in java programming courses. In Proceedings of the International Conference on Frontiers in Education: Computer Science and Computer Engineering (FECS) (p. 1). The Steering Committee of The World Congress in Computer Science, Computer Engineering and Applied Computing (WorldComp).

Das, A. (2015). Self Regulated Learning and Cognitive Styles of School Students - A Study, International Journal of Science and Research, 5(12), 1691-1694

Dille, B., Mezack, M. (1991). Identifying Predictors of High Risk among Community College Telecourse Students, The American Journal of Distance Education, 5(1), 11-19.

Falkner, K., Szabo, C., Vivian, R. and Falkner, N. (2015). Evolution of software development Strategies. In Proceedings of the 37th International Conference on Software Engineering. Florence, Italy.

Falkner, K., Vivian, R. and Falkner, N. (2014). Identifying Computer Science Self-Regulated Learning Strategies. In Proceedings of the 2014 Conference on Innovation \& Technology in Computer Science Education, 2, pp. 291-296.

Felder, R.M. \& Silverman, L.K. (1988). Learning and teaching styles in engineering education. Engineering Education, 78(7), 674-681.

Felder, R.M. \& Soloman, B. A. (1994). Index of Learning Styles. North Carolina State University, Retrieved January 06, 2017, from http://www.ncsu.edu/felder-public/ILSdir.html.

Felder, R.M., and Spurlin (2005). Applications, Reliability and Validity of the Index of Learning Styles. International Journal of Engineering Education, 21(1), 103-112.

Gülbahar, Y. (2005). Learning Styles and Technology, Education and Science, 30(138), 10-17.

Hui, H., Umar, I. (2011). Pair programming and lss in computing education: its impact on students' performances. US-China Education Review, 8(2), 613-626.

Hwang, G., Liang, Z. and Wang, H. (2016). An Online Peer Assessment-Based Programming Approach to Improving Students' Programming Knowledge and Skills. In Educational Innovation through Technology (EITT), 2016 International Conference on (pp. 81-85). Tainan, Tayvan: IEEE.

Kfee, B.J. (1988). The logic of message design: Individual differences in reasoning about communication. Communication Monographs, 55, 80-103. 
Kozlowski, S., Bell, B. (2006). Disentangling achievement orientation and goal setting: effects on self-regulatory processes. Journal of Applied Psychology, 900-916.

Kumar, V., Winne, P. H., Hadwin, A. F., Nesbit, J. C., Jamieson-Noel, D., Calvert, T., et al. (2005). Effects of self-regulated learning in programming. In Fifth IEEE International conference on advanced learning technologies (ICALT 2005) (pp. 383-387). IEEE.

Kuo, F., Wu, W. and Lin, C. (2013). An investigation of self-regulatory mechanisms in learning to program visual basic. Journal Educational Computing Research, 49(2), 225-247.

Lau, W., Yuen, A. (2011). Modeling programming performance: beyond the influence of learner characteristics. Computers \& Education, 571(1), 1202-1213.

Lavasani, M. G., Mirhosseini, F.S., Hejazi, E., Davoodi, M. (2011). The Effect of Self-regulation Learning Strategies Training on the Academic Motivation and Self-efficacy. Procedia Social and Behavioral Sciences, 29, $627-632$.

Lee, T.H., Shen, P.D., \& Tsai, C.W. (2010). Enhance students' computing skills via webmediated self-regulated learning with feedback in blended environment. International Journal of Technology and Human Interaction, 6(1), 15-32.

Li, P., Ko, A. and Zhu, J. (2015). What Makes a Great software Engineer? In Proceedings of the 37th International Conference on Software Engineering, Florence, Italy.

Liaw, S.S. \& Huang, H.M. (2013). Perceived satisfaction, perceived usefulness and interactive learning environments as predictors to self-regulation in e-learning environments. Computers \& Education, 60(1), 14-24.

Litzinger, T.A., Lee, S.H.; Wise, J.C., and Felder, R.M. (2007). A Psychometric Study of the Index of Learning Styles. Journal of Engineering Education, 96(4), 309-319.

Loksa, D., Ko, A. J., Jernigan, W., Oleson, A., Mendez, C. J., \& Burnett, M. M. (2016). Programming, problem solving, and self-awareness: effects of explicit guidance. In Proceedings of the 2016 CHI Conference on Human Factors in Computing Systems (pp. 1449-1461). ACM.

Lye, S. Y., Koh, J. H. L. (2014). Review on teaching and learning of computational thinking through programming: What is next for K-12?. Computers in Human Behavior, 41, 5161. https://doi.org/10.1016/j.chb.2014.09.012

Man-Chih, A. (2006). The effect of the use of self-regulated learning strategies on college students' performance and satisfaction in physical education (Unpublished Doctoral Dissertation). Australian Catholic University, Australia. Retrieved March 06, 2018, from https://doi.org/10.4226/66/5a94b7585e4cb

Nam, D., Kim, Y. and Lee, T. (2010). The Effects of Scaffolding-Based Courseware for the Scratch Programming Learning on Student Problem Solving Skill. In Proceedings of the 18th International Conference on Computers in Education, (pp. 723-727). Putrajaya, Malaysia.

Norwawi, N. M., Abdulsalam, S. F., Hibadullah, C. F. and Shuaibu, B. M. (2009). Classification Of Students' Performance in Computer Programming Course According to Learning Style. Data Mining and Optimization. Kajand, Malaysia.

Paechter, M., Maier, B., and Macher, D. (2010). Students' expectations of and experiences in e learning: Their relation to learning achievements and course satisfaction. Computers \& Education, 54(1), 222-229.

Paris,W. (2001). The role of self-regulated learning in contextual teaching: principles and practices for teacher preparation. Retrieved 11 April 2018, from https:/files.eric.ed.gov/fulltext/ED479905.pdf

Pintrich , P. R., Smith, D.A., Garcia, T.,and McKeachie, W. J. (1991). A manual for the use of the motivated strategies for learning questionnaire (MSLQ). University of Michigan, Ann Arbor.

Pintrich, P. R.(2004). A conceptual framework for assessing motivation and self-regulated learning in college students. Educational Psychology Review, 16(4), 385-407

Pintrich, P. R., De Groot, E. V. (1990). Motivational and self-regulated learning components of classroom academic performance. Journal of Educational Pschology, 82, 33-40.

Pintrich, P.R. (2000). A motivational science perspective on the role of student motivation in learning and teaching contexts. Journal of Educational Psychology, 95, 667-686.

Puzziferro, M. (2008). Online technologies self-efficacy and self-regulated learning as predictors of final grade and satisfaction in college-level online courses. American Journal of Distance Education, 22(2), 72-89. 
Ramalingam, V., LaBelle, D. and Wiedenbeck, S. (2004). Self-efficacy and mental models in learning to program, In Proceedings of the 9th annual SIGCSE conference on Innovation and technology in computer science education, June 28-30, 2004, Leeds, United Kingdom.

Saeli, M., Perrenet, J., Jochems, W. and Zwaneveld, B. (2011). Teaching programming in secondary school: a pedagogical content knowledge perspective. Informatics in Education, 10(1).

Safari, E., Hejazi, M. (2017). Learning styles and self-regulation: an associational study on high school students in iran. Mediterranean Journal of Social Sciences, 8(1), 463-469.

Schunk, D.H. \& Zimmerman, B. J. (Eds.). (1998). Self-regulated learning: From teaching to self reflective practice. New York: Guilford Press.

Shannon, S.V. (2008). Using metacognitive strategies and learning styles to create self-directed learners. Institute for Learning Styles Journal, 1,14-28.

Wang, C., Shannon, D., and Ross, M. (2013). Students' Characteristics, Self-Regulated Learning, Technology, Self-Efficacy, and Course Outcomes in Online Learning. Distance Education, 34(3), 302-323.

Wiedenbeck, S. (2005). Factors affecting the success of non-majors in learning to program, In Proceedings of The First International Workshop on Computing Education Research, 13-24, Seattle, WA, USA.

Wiedenbeck, S., LaBelle, D. and Kain, V. (2004). Factors affecting course outcomes in introductory programming. In Proceedings of the Sixteenth Annual Workshop of the Psychology of Programming Interest Group (PPIG' 04) (pp. 97-109).

Zhang, L., Jia, J., Wang, B., Amanai, K., Wharton, K. A., \& Jiang, J. (2006). Regulation of wingless signaling by the CKI family in Drosophila limb development. Developmental Biology, 299(1), 221-237.

Zimmerman, B. J. (2008). Investigating self-regulation and motivation: Historical, background, methodological developments, and future prospects. American Educational Research Journal, 45, 166-183.

Zimmerman, B. J., \& Martinez-Pons, M. (1990). Student differences in self-regulated learning: Relating grade, sex, and giftedness to selfefficacy and strategy use. Journal of Educational Psychology, 82, 51-59.

Zimmerman, B.J. (2002). Becoming a Self-Regulated Learner: An Overview, Theory Into Practice, 41(2), 64-70,

Zywno, M. S. (2003). A contribution to validation of score meaning for Felder-Soloman's index of learning styles. In Proceedings of the 2003 American Society for Engineering Education Annual Conference \& Exposition (Vol. 119, pp. 1-5). Washington, DC: American Society for Engineering Education. 


\section{APPENDIX-1}

The questions directed to assess individual factors are as follows:

Task value: "Why do you think the programming languages course is necessary for your education?"

External target orientation: "What is your objective with the programming languages course?"

Target setting: "What kind of objectives you aim for before starting with programming?"

Self-efficacy:: "Which skills give you an edge in authoring the programs to solve complex problems?"

Self-reflection: "What kind of problems you experience in program writing process? What do you do in response to the errors you face?"

Repetition: "How do you get prepared for the programming exam?"

Peer-learning: "What kind of assistance you expect your friends to provide for the programming languages course, and when?"

Time management: "How do you plan your time for use regarding the programming course? Do you think you set aside sufficient time for the course and the exam? Why?"

Effort regulation: "What do you do to proceed when you face any problem regarding the programming process?"

\section{APPENDIX-2}

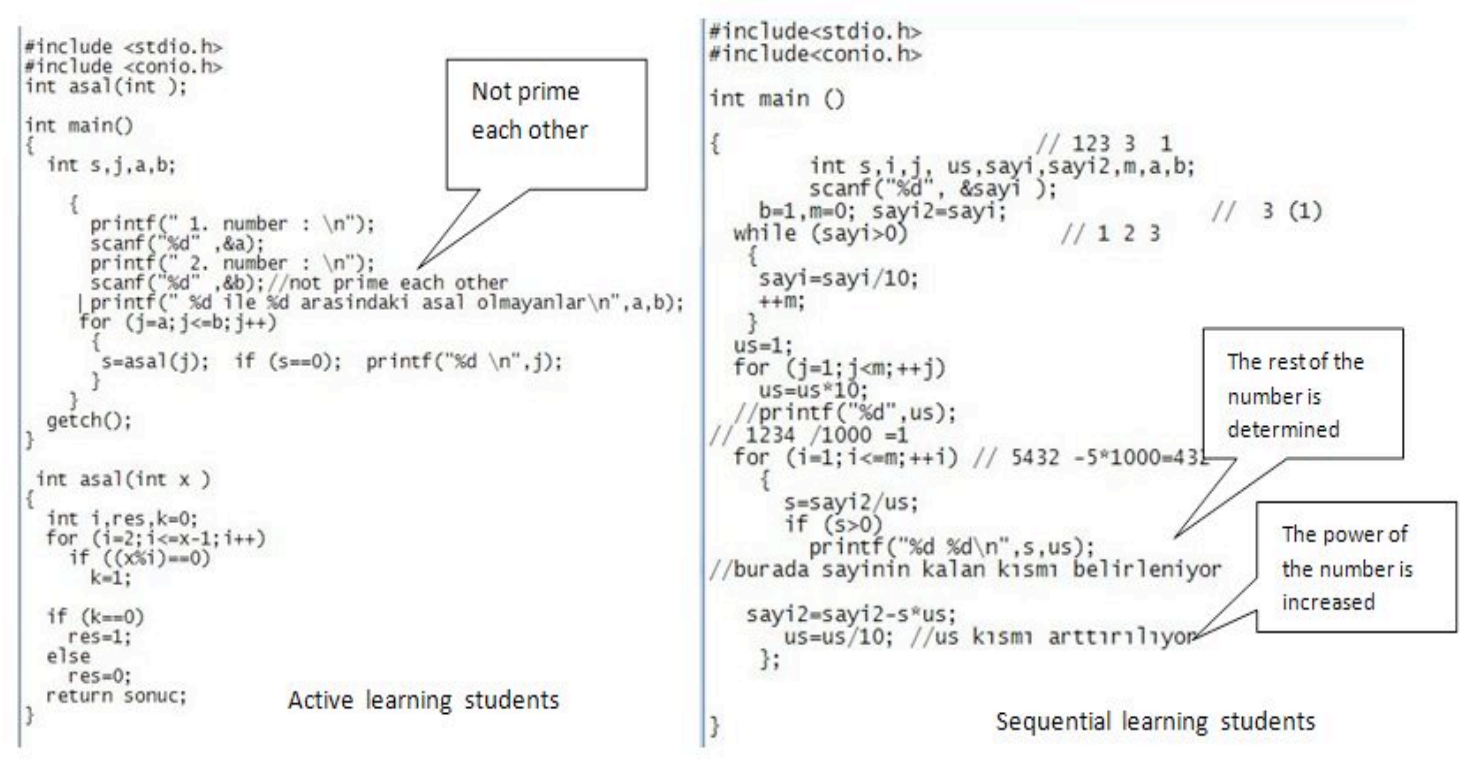

